\title{
An Integrated Approach to Characterize the Dynamic Behaviour of a Mechanical Chain Tensioner by Functional Tolerancing
}

\author{
Michele Calì ${ }^{1}$ * - Salvatore Massimo Oliveri ${ }^{1}$ - Rita Ambu ${ }^{2}$ - Gabriele Fichera ${ }^{3}$ \\ 1University of Catania, Electric, Electronics and Computer Engineering Department, Italy \\ 2University of Cagliari, Department of Mechanical, Chemical and Materials Engineering, Italy \\ 3 University of Catania, Civil Engineering and Architecture Department, Italy
}

Assembled systems composed of flexible components are widely used in mechanics to dampen vibrations and store or dissipate energy. Often, the flexible components of these systems are assembled via non-linear sliding contacts and yielding constraints. Geometric non-linearity along with non-linearity of stiffness, damping and contact pressure between flexible components greatly complicate the dynamic characterization of these assemblies. Therefore, such assemblies are characterised almost exclusively by means of experimental testing.

This research analyses how classic ASME and ISO tolerance standards can be used to guarantee and control the conformity of these assembled systems with their functional requirements limiting the number of experimental tests. In particular the dependence of the dynamic behaviour upon functional tolerances is studied for a mechanical tensioner in a chain drive timing system of an internal combustion engine (ICE). The semi empirical methodology is based on displacement measurements and modal analyses. A multibody model with few degrees of freedom (MBM-FDoF) is proposed as the first approximation to reproduce the variability of the dynamic behaviour of the tensioner considering variations in functional tolerances.

Keywords: ASME-ISO tolerance specification, reverse engineering, tensioner, deformation energy, multibody model

Highlights

- Dynamic behaviour of assembled systems composed of flexible components was analysed.

- $\quad$ ASME and ISO tolerance standards are used to guarantee and control the conformity of assembled systems with functional requirements.

- A multibody model with few degrees of freedom validated with modal analysis allowed to control the variability of the assembled system.

\section{INTRODUCTION}

In the aerospace and automotive industries $65 \%$ to $70 \%$ of failures and breakdowns of mechanical systems are caused by geometric and/or size variations whose consequences were not accurately predicted during the design phase [1]. Dimensional and geometrical variations can significantly influence the functionality of assembled mechanical systems, especially those consisting of highly deformable components subjected to shock and vibration [2] and [3]. These systems characterized by the presence of sliding contacts and yielding constraints are generally used in mechanics to dampen vibrations and store or dissipate energy. Their reliability is as important as the need to precisely predict and control the variability of their dynamic characteristics since their geometrical properties (e.g. shape and dimension) are subjected to change. Examples of such assemblies include civil, military, automotive, naval and aerospace applications [4] to [6].

According to the available numerical analysis methods (i.e. finite element method (FEM) and multibody), simulations of these systems appear to be particularly complex, since it is difficult to determine the presence of extended sliding contacts and moving impacts between flexible components, as well as a high degree of geometric non-linearity [7] and [8]. Usually constitutive equations or rate constitutive equations are used in finite element software to model these systems and characterization of such systems is carried out by means of experimental testing [9] and [10].

This study proposes a replicable semi -empirical procedure, based on few targeted experimental displacement measurements and modal analyses, where functional tolerance specifications are used to predict and control the variability of the dynamic behaviour in such systems.

The actual tolerance specifying method is geometric dimensioning and tolerancing (GD\&T) as indicated in the ASME Y14.5 [11] and ISO 1101 [12] standards. The application of GD\&T can be ensured by different approaches, mainly attributable to tolerance analysis and tolerance synthesis. In tolerance analysis [13] and [14] the contribution to the accumulation of variations at one or more functional features in a tolerance stack-up is considered, while tolerance synthesis [15] to [17] studies the influence of geometrical variations in parts on the behaviour of a 
mechanism and on its functional requirements, since, generally, geometrical variations in parts are due to the degradation of the functional characteristics of a mechanism.

In the present research, GD\&T approach is used to control the influence of functional tolerances on the dynamic behaviour of a mechanical tensioner for internal combustion engine (ICE) chain drive timing systems. Functional dimensioning of each component is obtained by selecting the features which establish the datum reference frame (DRF) and attributing appropriate typology and values to geometrical errors.

Furthermore, a mathematical model, based on multibody formulation with few degrees of freedom (MBM-FDoF), has been proposed in order to predict and control the variability of dynamic characteristics in the tensioner depending on the variations in functional tolerances.

The mechanical tensioner inserted in the ICE chain drive timing system displays significant geometric and contact nonlinearities. It consists of highly deformable components which come into direct contact due to the forces acting on the system, changing the load path, stress state and dissipated deformation energy [5] and [9]. The case study demonstrates that the appropriate assignment of functional tolerances allows predicting and controlling the variability of dynamic system behaviour without resorting to complex and expensive experimental tests. In particular, functional dimensioning is used to control couplings whose interference influences the dynamic behaviour of the system.

The paper is organized as follows: in Section 1 functional dimensioning of the components is described in relation to the initial design and operating conditions of the tensioner. Section 2 illustrates the construction of the MBM-FDoF capable to reproduce efficiently the dynamic behaviour and the frequency response of the tensioner. In Section 3 the dynamic characterization of the tensioner is carried out via modal analysis and displacement measurements. In Section 4 the functional tolerances that have an impact on the dynamic behaviour of the tensioner are identified and the influence of the variation in tolerances on the dissipated energy and the flexibility of the tensioner are studied. In Section 5 closing remarks and conclusions are finally reported.

\section{FUNCTIONAL DIMENSIONING OF THE TENSIONER COMPONENTS}

The tensioner is a part of the primary stage chain drive timing system in a high performance V-12 ICE studied by the authors in recent scientific publications [9] and [10]. The tensioner consists of five parts: bracket, blade and three equal leaf springs (Fig. 1a). The steel bracket holds the polyamide (PA 66) blade with a pin, and a bracket shelf allows the blade to flex, which transmits the damped transverse forces of the chain to the cylinder block and ensures proper chain meshing on the sprocket (Fig. 1b).
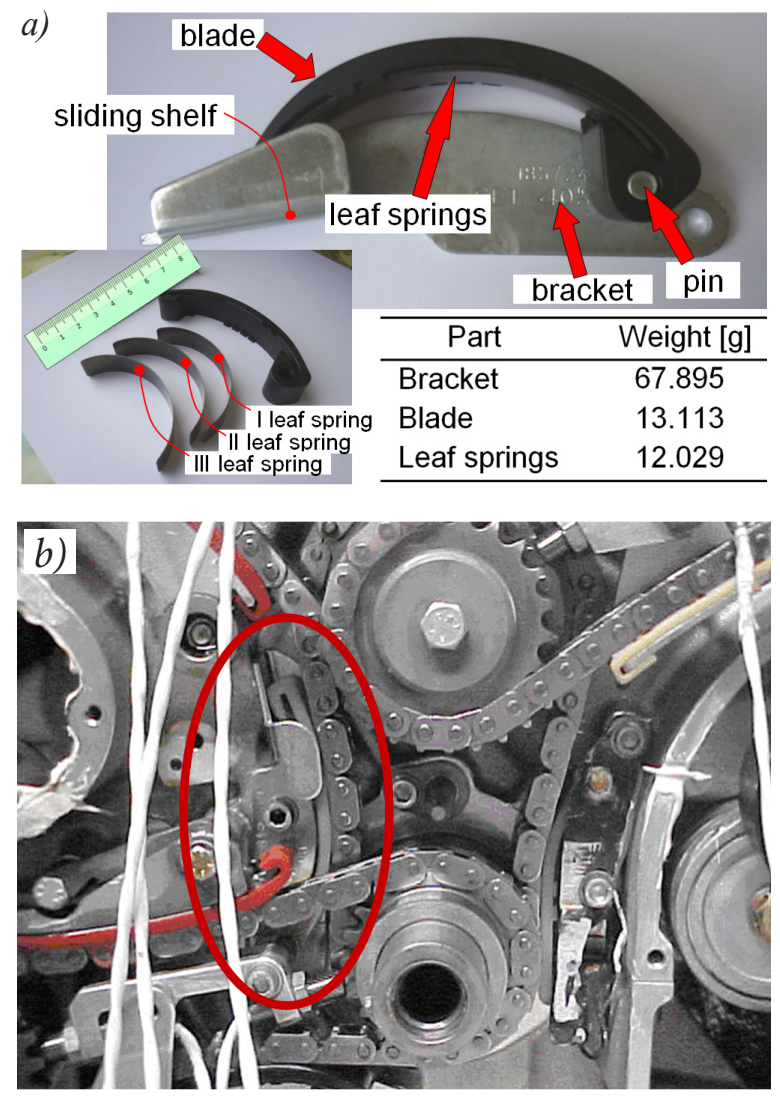

Fig. 1. Mechanical tensioner: a) system components; b) positioning in primary stage of timing chain drive

The three leaf springs are held in the internal concave seat of the blade. The tensioner plays an important role in the isolation and damping of transient mechanical vibrations in chain drive timing systems, mitigating undesirable effects such as wear, noise and fatigue. These latter capabilities are correlated to the quantity of energy the tensioner can dissipate.

Complete functional dimensioning is accomplished by the assignment of dimensional and geometrical tolerances to the components of the assembly according to the ASME international standards [11]. In particular, the couplings between the blade and the leaf springs and between the blade and the bracket were characterized. 
The first step in functional dimensioning consists of the definition of DRF, based on the functionality and precision in manufacturing the features of the components (internal and external bracket surfaces, bracket hinge pin).

Manufacturing accuracy of bracket, blade and leaf springs was evaluated considering available information selected in literature [18] to [21]. Blade, in polyamide, is created through a pressure-melted operation. Leaf springs derive from rolling, whereas bracket is produced by a developer cut plate fold for moulding.

The selected datums are the most suitable ones for the control of the dimensional and geometrical tolerances related to manufacturing, whose variability due to assembling and/or wear significantly influences the dynamic behaviour of the tensioner, as reported in Section 3.

The dimensioning scheme of the blade reported in Fig. 2 takes into account all these factors. All dimensions and tolerances apply to a free-state condition, as required by the ASME standard [11].

The tolerances for size/profile are selected according to the most achievable degree of accuracy in the die casting process for the manufacture of polyamide [19] and [20].

The primary datum of the blade, indicated as A in Fig. 2, is the hole which, coupled with the hinge pin of the bracket, enables the rotation of the blade.

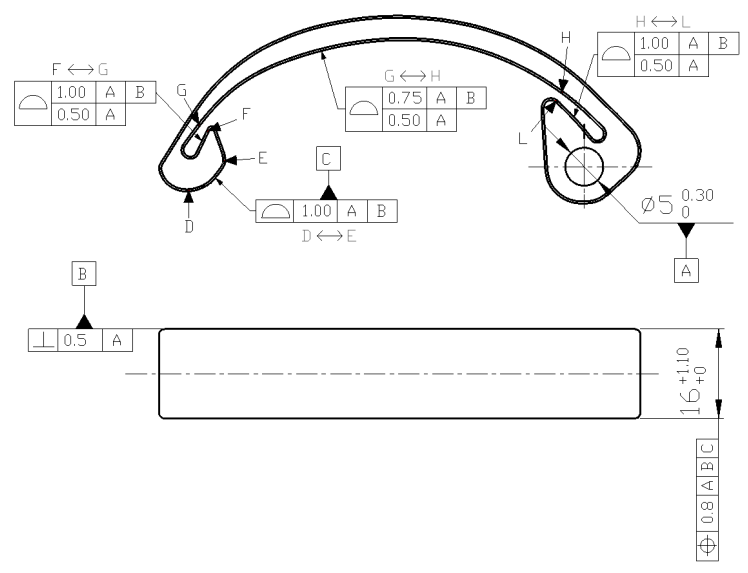

Fig. 2. Functional dimensioning scheme of the blade

The secondary datum $B$ is the plane perpendicular to the axis of the hole and is located on the back of the blade. The tertiary datum $\mathrm{C}$ is determined by the surface in contact with the bracket shelf during device operation.

Complementary datums were selected for the bracket. In particular, the primary datum A is the hinge pin around which the blade rotates. The secondary datum $B$ is the internal surface of the bracket, while the tertiary datum $\mathrm{C}$ is determined by the shelf surface of the bracket in contact with the blade during tensioner operation (Fig. 3).

The DRF determined by the datums of the blade and the bracket allows introducing an orthogonal coordinate system (Fig. 4), which can be used to characterize the tensioner in terms of stiffness and damping, and to measure displacement and deformation.
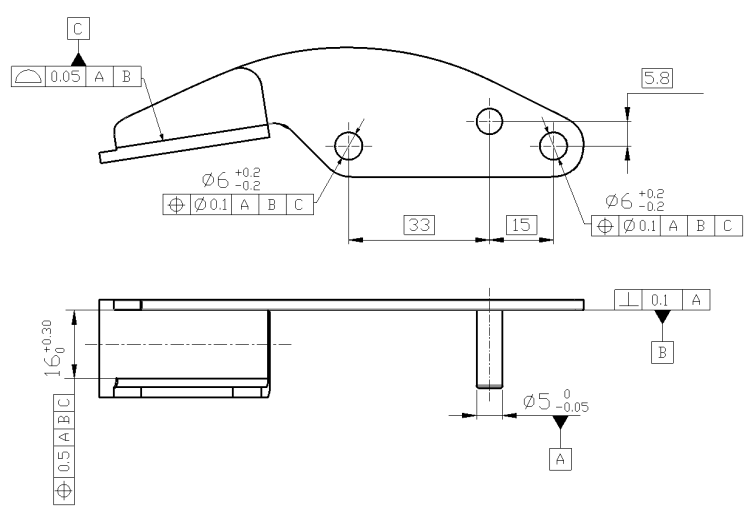

Fig. 3. Functional dimensioning scheme of the bracket

The origin of this coordinate system is on the inner surface of the bracket, where the $z$ axis coincides with the hinge pin axis while the $y$ axis is parallel to the bracket shelf.

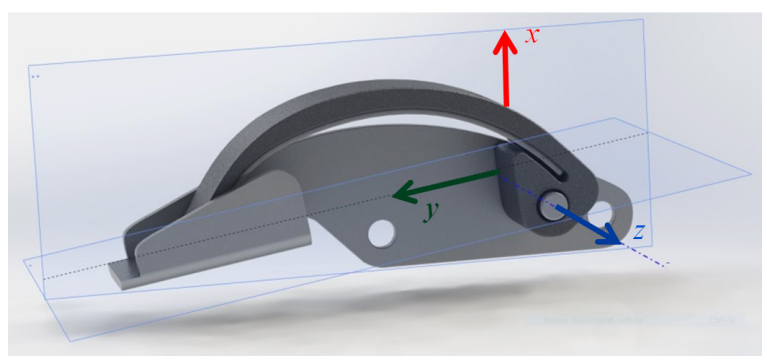

Fig. 4. Coordinate system in blade-bracket assembly

Profile tolerances allow shape and position errors to be checked, including orientation of surfaces. They are particularly suitable for controlling the polycentric profile of blade and springs. Fig. 5 reports the functional dimensioning scheme of the leaf springs [22], which, in conjunction with the functional dimensioning of the blade shown in Fig. 2, allows all the interactions among these components to be taken into account.

In the coupling between the first (upper) spring and the inner surface of the blade, the tolerances refer 
to the ideal profiles (a polycentric curve with three curvatures) specified in Section 2. The reciprocal position and orientation of the springs are determined by their coupling with the bottom ends of the blade.

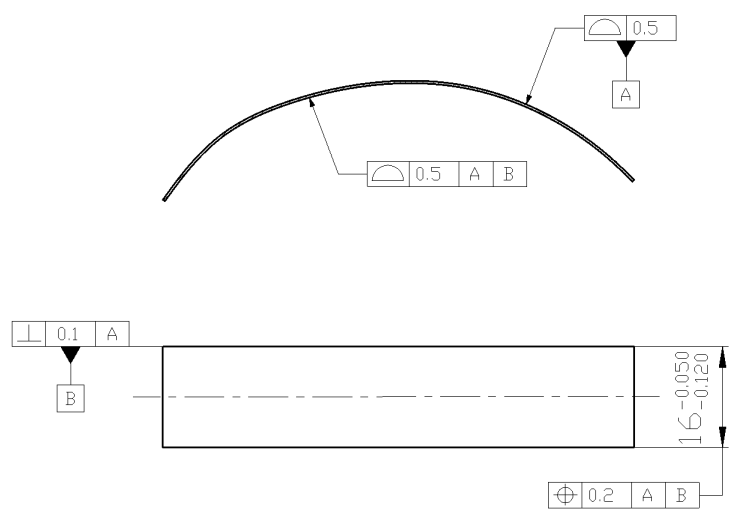

Fig. 5. Functional dimensioning of the leaf spring

Plane B plays an important role in controlling the geometrical errors between the springs and the blade since the reciprocal orientation of the components in contact with this plane determines the overall arrangement during device operation.

\section{NUMERICAL MODELLING}

An MBM-FDoF was created using a MSC ADAMS ${ }^{\circledR}$ commercial code so obtaining some effective numerical tools able to predict and control which effects functional tolerance variations have on tensioner's dynamic behaviour.

A detailed finite element (FE) model was also generated (using ANSYS ${ }^{\circledR}$ commercial code ver. 17.0) to accurately evaluate structural deformation, stress state, frictional sliding contact forces and yielding constraints (Fig. 6a).

In the FE model the coupling regions of contact were modelled with ANSYS ${ }^{\circledR}$ frictional sliding contact; this type of connection is able to accurately reproduce the sliding contact with friction even in the presence of high deformations [8]. Due to the presence of lubrication a regularized friction law was used with low values of coefficient of friction $\left(\mu_{\text {static }}=0.1\right.$; $\mu_{\text {dynamic }}=0.05$ ) [23] and [24].

Blade design shape was acquired by reverse engineering technique with a laser scanner (Konica Minolta 9v-I, precision $\leq 10 \mu \mathrm{m}$ ). Final $3 \mathrm{D}$ reconstruction has been optimized (border regularization) using the method reported in [25]. To ensure a realistic dynamic behaviour of tensioner during numerical simulation enabling the contact

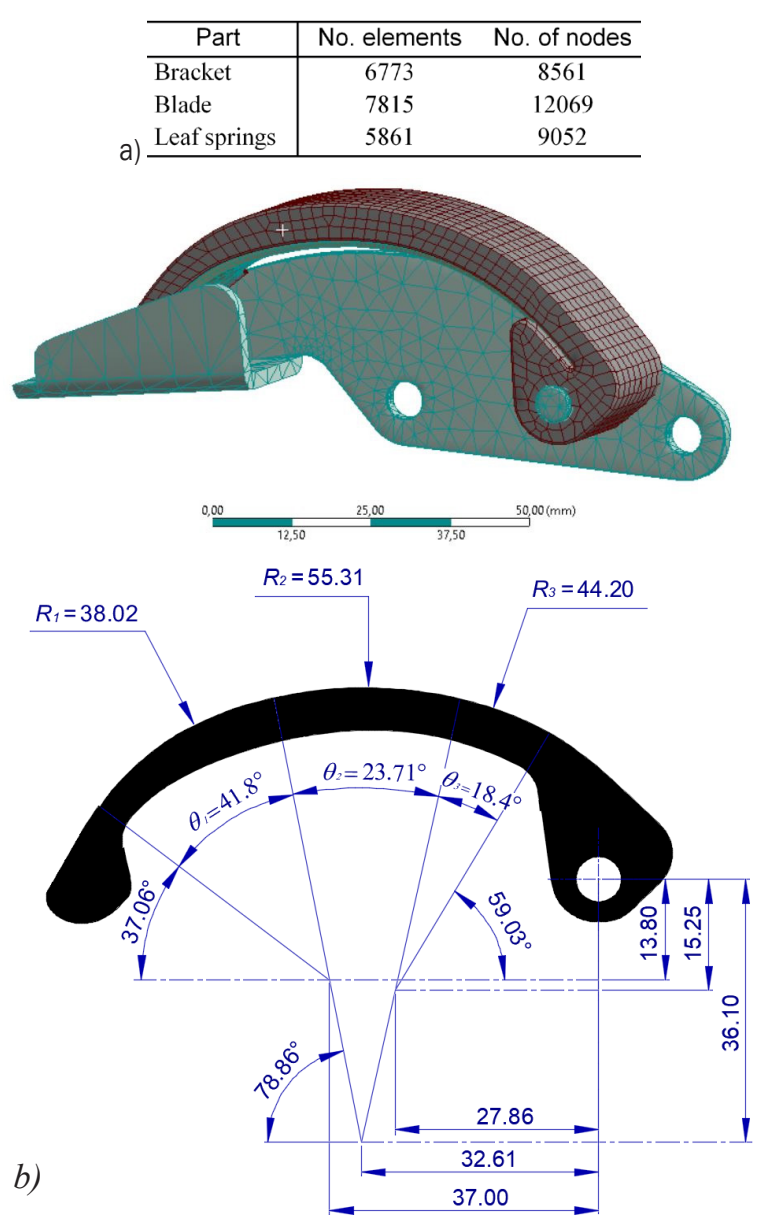

Fig. 6. a) Tensioner FE model; and b) blade subdivision

between tensioner's external surface and the chain links in multibody simulations of the entire timing, the blade shape was divided in three contiguous sectors of hollow cylindrical sections with external radiuses $R_{1}, R_{2}$ and $R_{3}$ and angular extensions $\mathrm{q}_{1}$, $\mathrm{q}_{2}$ and $\mathrm{q}_{3}$ (Fig. 6b). The curvature profile continuity of the blade's outer surface during deformation has been guaranteed with geometric constraints, applied to the radiuses $R_{1}, R_{2}$ and $R_{3}$ and angles $\mathrm{q}_{1}, \mathrm{q}_{2}$ and $\mathrm{q}_{3}$. The geometric constraints keep the three external cylindrical surfaces with $C_{1}$ continuity in the points they have in common. Furthermore, the three radiuses and the three angles were assigned so that the flexible components could be subdivided into an integer number $n$ of equal parts. The number of partitions was selected in accordance with the "modal basis" concept, i.e. the number of modes necessary to approximate the system response within the frequency range of forces [26] and [27]. It was demonstrated by [21] that once the range of interest is established $\left(\Omega_{\min }\right.$ 
$\left.-\Omega_{\max }\right)$, the modal basis can be formed considering all the modes whose frequency is $\omega_{i}<2 \Omega_{\max }$. The $n$ parts are interconnected by elastic-damping forces and dynamically characterize the model according to the experimental data of displacement measurements and modal analysis.

The accuracy of results obtained by the MBMFDoF was confirmed by comparing them with experimental data. Fig. 7 summarizes the described methodology in detail.

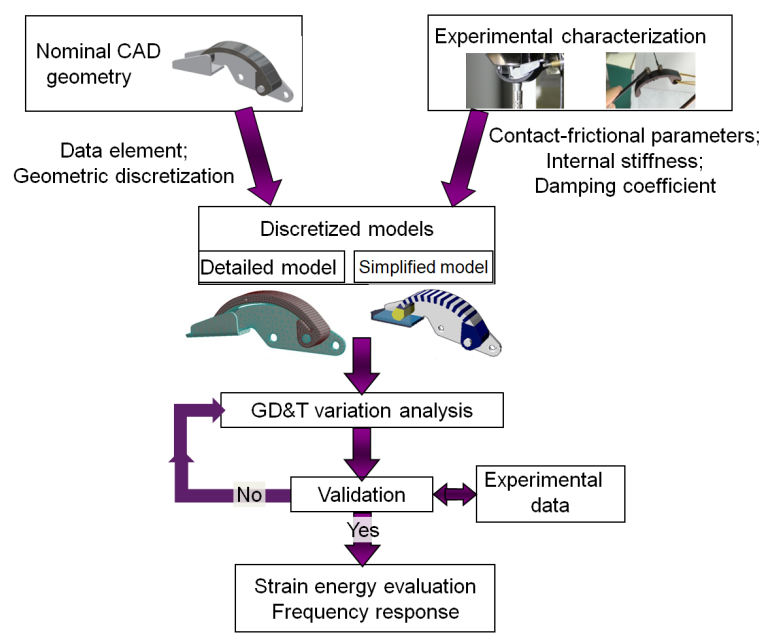

Fig. 7. Work flow of the implemented methodology

According to the frequency values calculated below, the tensioner was subdivided into 22 parts (Fig. 8).

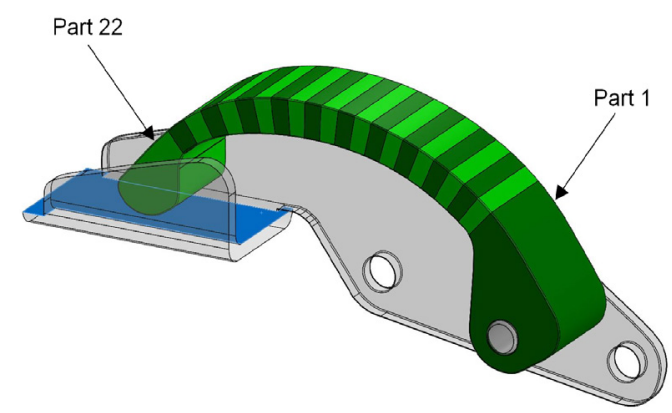

Fig. 8. FDoF multibody model

Table 1. Mechanical properties of equivalent material

\begin{tabular}{lccc}
\hline Parameter & PA 66 & $\begin{array}{c}\text { Steel } \\
48 S 17\end{array}$ & $\begin{array}{c}\text { Equivalent } \\
\text { material }\end{array}$ \\
\hline Young's modulus [N/mm²] & 4000 & 210000 & 28000 \\
\hline Density $\left[\mathrm{kg} / \mathrm{m}^{3}\right]$ & 1345 & 7810 & 3200 \\
\hline Poisson's ratio & 0.34 & 0.3 & 0.33 \\
\hline
\end{tabular}

Part 1 was hinged by the pin to the bracket whereas part 22 was constrained unilaterally to slide along the bracket shelf at the end of the bracket. In this way the model has $20 \times 6+2+1=123 \mathrm{DoF}$.

Twenty central parts of equal volume and mass have the same equivalent inertial density, the weighted mean lying between the polyamide density and that of the leaf spring steel (Table 1).

Two adjacent parts are linked at their centres of mass by general forces (GF). In this way parts exchange axial, flexional and torsional elasticdamping forces in three mutually right-angled directions (Fig. 9).

The elastic force components are linear whereas the damping force components are viscous, and proportional to the velocity of the centres of mass which they connect.
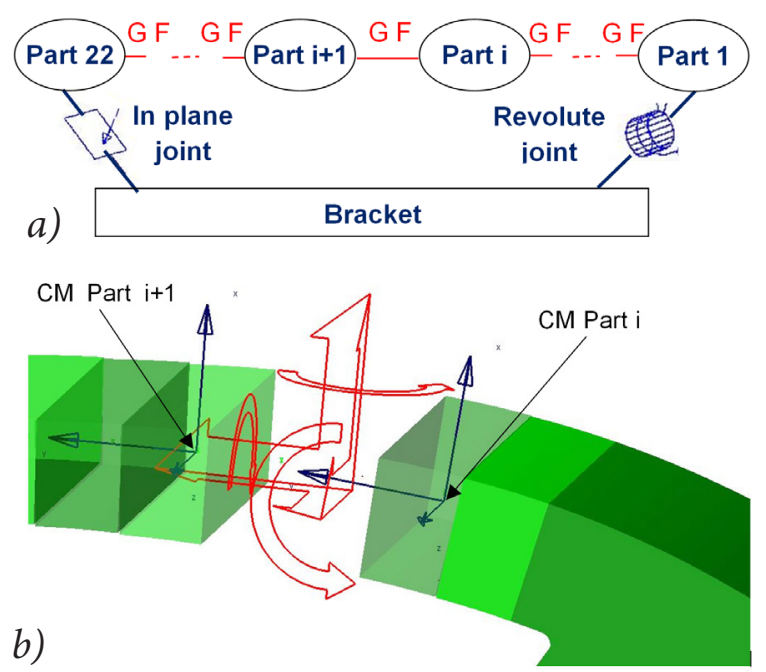

Fig. 9. Connection between parts with general force (GF): a) schematic diagram; and b) application points in MBM-FDoF

Compared to the orthogonal coordinate system originating in the centre of mass (CM) of part $i$, and the $y$ axis oriented towards the $\mathrm{CM}$ of part $i+1$, the six $\mathrm{GF}^{i}$ components applied on part $i$ can be written as follows:

$$
\begin{aligned}
& \vec{F}_{x}^{i}=k_{x}^{i}\left(\vec{q}_{x}^{i}-\vec{q}_{x}^{i+1}\right)+c_{x}^{i}\left(\overrightarrow{\dot{q}}_{x}^{i}-\overrightarrow{\dot{q}}_{x}^{i+1}\right), \\
& \vec{F}_{y}^{i}=k_{y}^{i}\left(\vec{q}_{y}^{i}-\vec{q}_{y}^{i+1}\right)+c_{y}^{i}\left(\overrightarrow{\dot{q}}_{y}^{i}-\overrightarrow{\dot{q}}_{y}^{i+1}\right), \\
& \vec{F}_{z}^{i}=k_{z}^{i}\left(\vec{q}_{z}^{i}-\vec{q}_{z}^{i+1}\right)+c_{z}^{i}\left(\overrightarrow{\dot{q}}_{z}^{i}-\overrightarrow{\dot{q}}_{z}^{i+1}\right), \\
& \vec{F}_{\vartheta}^{i}=k_{\vartheta}^{i}\left(\vec{q}_{\vartheta}^{i}-\vec{q}_{\vartheta}^{i+1}\right)+c_{\vartheta}^{i}\left(\overrightarrow{\dot{q}}_{\vartheta}^{i}-\overrightarrow{\dot{q}}_{\vartheta}^{i+1}\right), \\
& \vec{F}_{\varphi}^{i}=k_{\varphi}^{i}\left(\vec{q}_{\varphi}^{i}-\vec{q}_{\varphi}^{i+1}\right)+c_{\varphi}^{i}\left(\overrightarrow{\dot{q}}_{\varphi}^{i}-\overrightarrow{\dot{q}}_{\varphi}^{i+1}\right), \\
& \vec{F}_{\psi}^{i}=k_{\psi}^{i}\left(\vec{q}_{\psi}^{i}-\vec{q}_{\psi}^{i+1}\right)+c_{\psi}^{i}\left(\overrightarrow{\dot{q}}_{\psi}^{i}-\overrightarrow{\dot{q}}_{\psi}^{i+1}\right),
\end{aligned}
$$


where $k^{i}$ are stiffness coefficients and $c^{i}$ damping coefficients. The components $\vec{F}_{\vartheta}^{i}, \vec{F}_{\psi}^{i}$ and $\vec{F}_{\varphi}^{i}$ are flexional moment in $y z$ plane, flexional moment in $x y$ plane and torsional moment around the $y$ axis, respectively.

Associating the dependent coordinate vector $\mathbf{q}(x, y, z, \vartheta, \varphi, \psi)$ to each part and using the Lagrange multipliers technique, the following differential algebraic equations (DAE) are obtained, describing the tensioner's deformation movements:

$$
\left[\begin{array}{cc}
\mathbf{M} & \boldsymbol{\Phi}_{q}^{T} \\
\Phi_{q} & \mathbf{0}
\end{array}\right]\left[\begin{array}{l}
\ddot{\mathbf{q}} \\
\lambda
\end{array}\right]=\left[\begin{array}{l}
\mathbf{Q} \\
\gamma
\end{array}\right],
$$

where $\mathbf{Q}(t)$ is the vector which gathers the internal, external and complementary inertia forces (Coriolis forces), $\mathbf{M}$ is the mass (and inertial) matrix, $\boldsymbol{\Phi}_{q}$ is the gradient of constraints (Jacobian), $\boldsymbol{\lambda}$ is the Lagrange multipliers vector, $\boldsymbol{\gamma}$ is the vector that groups all the terms of the acceleration constraint equations that depend on velocities. $\mathbf{Q}(t)$ include GF and constraint reactions in the extremities (part 1 and part 22).
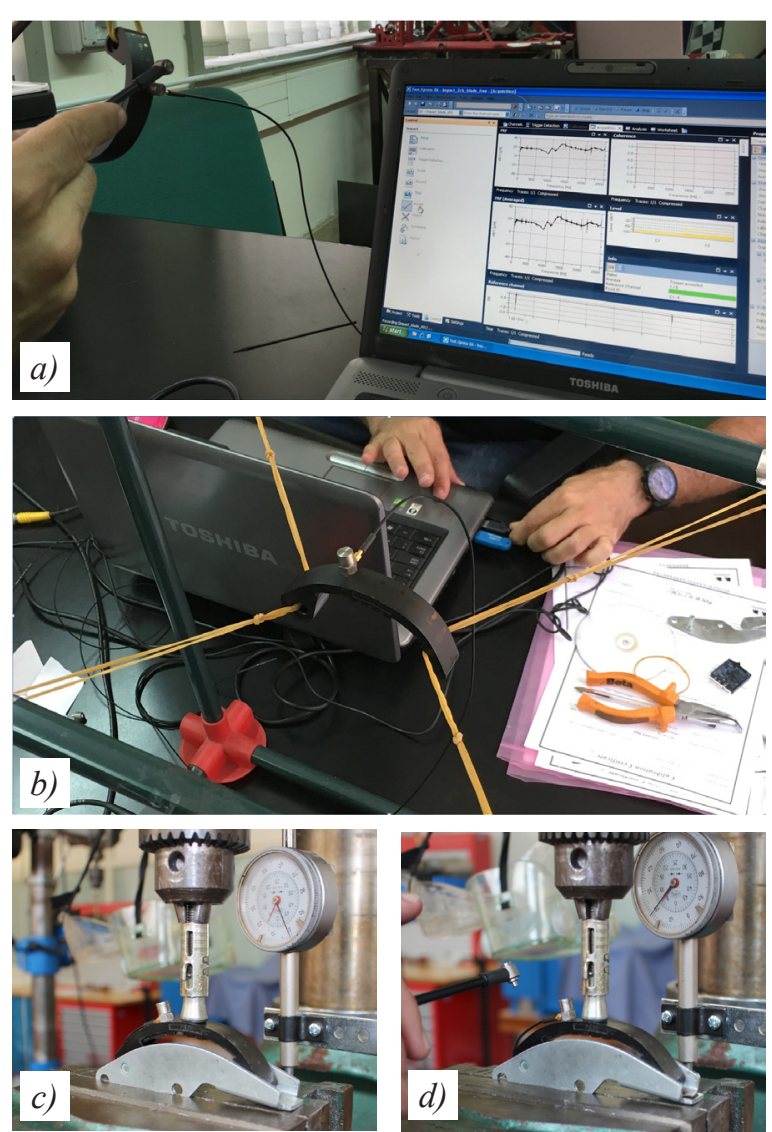

Fig. 10. Modal analysis: a) data acquisition front-end; b) free-free $E M A ; c)$ and d) loaded EMA
By means of design of experiment (DoE) analysis, in Section 4 the best fitting stiffness $\left(k^{i}\right)$ and damping (ci) coefficient values in the GF are determined to reproduce the system's dynamic behaviour in terms of frequency response and cyclic deformations.

\section{DYNAMIC CHARACTERIZATION}

The dynamic characterization of the tensioner was performed by means of modal analysis and cyclic deformation tests. The experimental modal analysis (EMA) was carried out by roving hammer impact test, with a Brüel \& Kjær piezoelectric charge hammer and a small size charge accelerometer (Figs. 10a and d).

Front-end data and specific software (Test Xpress, TestLab) from Siemens/LMS were used for the acquisition of signals, post-processing, FRF calculation and complete identification of main modes.

The blade with leaf springs was tested under different constraint conditions: free-free body (Figs. $10 \mathrm{a}$ and $\mathrm{b}$ ), and constrained operational configuration with three different vertical loads, whose values were set to a minimum level of $21.6 \mathrm{~N}$ (static pre-load: $F_{\text {pre }}$ ), a mean level of $80.0 \mathrm{~N}$ (mean load: $F_{\text {mean }}$ ) and

Table 2. Tensioner frequencies, modal damping and mode shapes descriptions

\begin{tabular}{|c|c|c|c|c|}
\hline & Mode & $\begin{array}{l}\text { Freq. } \\
{[\mathrm{Hz}]}\end{array}$ & $\begin{array}{c}\text { Damping } \\
{[\%]}\end{array}$ & Description \\
\hline \multirow{5}{*}{ 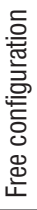 } & $1^{\circ}$ & 413.18 & 5.42 & Bending mode in $x y$ plane \\
\hline & $2^{\circ}$ & 1054.7 & 5.41 & Longitudinal torsion mode \\
\hline & $3^{\circ}$ & 1938.7 & 5.03 & Bending and torsion mode \\
\hline & $4^{\circ}$ & 2267.2 & 4.34 & Bending mode in yz plane \\
\hline & $5^{\circ}$ & 3222.8 & 5.20 & Bending and torsion mode \\
\hline \multirow{5}{*}{ 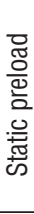 } & $1^{\circ}$ & 287.04 & 5.61 & Bending mode in $x y$ plane \\
\hline & $2^{\circ}$ & 657.55 & 5.56 & Bending mode in $x y$ plane \\
\hline & $3^{\circ}$ & 987.39 & 5.09 & Bending mode in $x y$ plane \\
\hline & $4^{\circ}$ & 1416.5 & 4.84 & Longitudinal torsion mode \\
\hline & $5^{\circ}$ & 1976.0 & 5.21 & Bending mode of leaf springs \\
\hline \multirow{5}{*}{$\begin{array}{l}\text { ్ㅠ } \\
\text { ్ㅡㄹ } \\
\text { ్ㅀㅀ } \\
\stackrel{\mathbb{J}}{\Sigma}\end{array}$} & $1^{\circ}$ & 290.78 & 5.73 & Bending mode in $x y$ plane \\
\hline & $2^{\circ}$ & 655.47 & 5.67 & Bending mode in $x y$ plane \\
\hline & $3^{\circ}$ & 985.48 & 5.51 & Bending mode in $x y$ plane \\
\hline & $4^{\circ}$ & 1410.1 & 5.81 & Longitudinal torsion mode \\
\hline & $5^{\circ}$ & 2184.1 & 5.25 & Bending mode of leaf springs \\
\hline \multirow{5}{*}{ 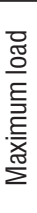 } & $1^{\circ}$ & 296.61 & 6.37 & Bending mode in $x y$ plane \\
\hline & $2^{\circ}$ & 653.95 & 5.71 & Bending mode in $x y$ plane \\
\hline & $3^{\circ}$ & 982.56 & 5.61 & Bending mode in $x y$ plane \\
\hline & $4^{\circ}$ & 1403.6 & 5.85 & Longitudinal torsion mode \\
\hline & $5^{\circ}$ & 1971.8 & 5.37 & Bending mode of leaf springs \\
\hline
\end{tabular}


a maximum level of $138.3 \mathrm{~N}$ (maximum load: $F_{\max }$ ) (Figs. 10c and d).

As outlined by the authors in Calì et al. [8], the values of preload, mean load and maximum load were experimentally determined by tensioner measurement at static test bench.

Experimental frequency, modal damping and mode shapes resulting from EMA are reported in Table 2.
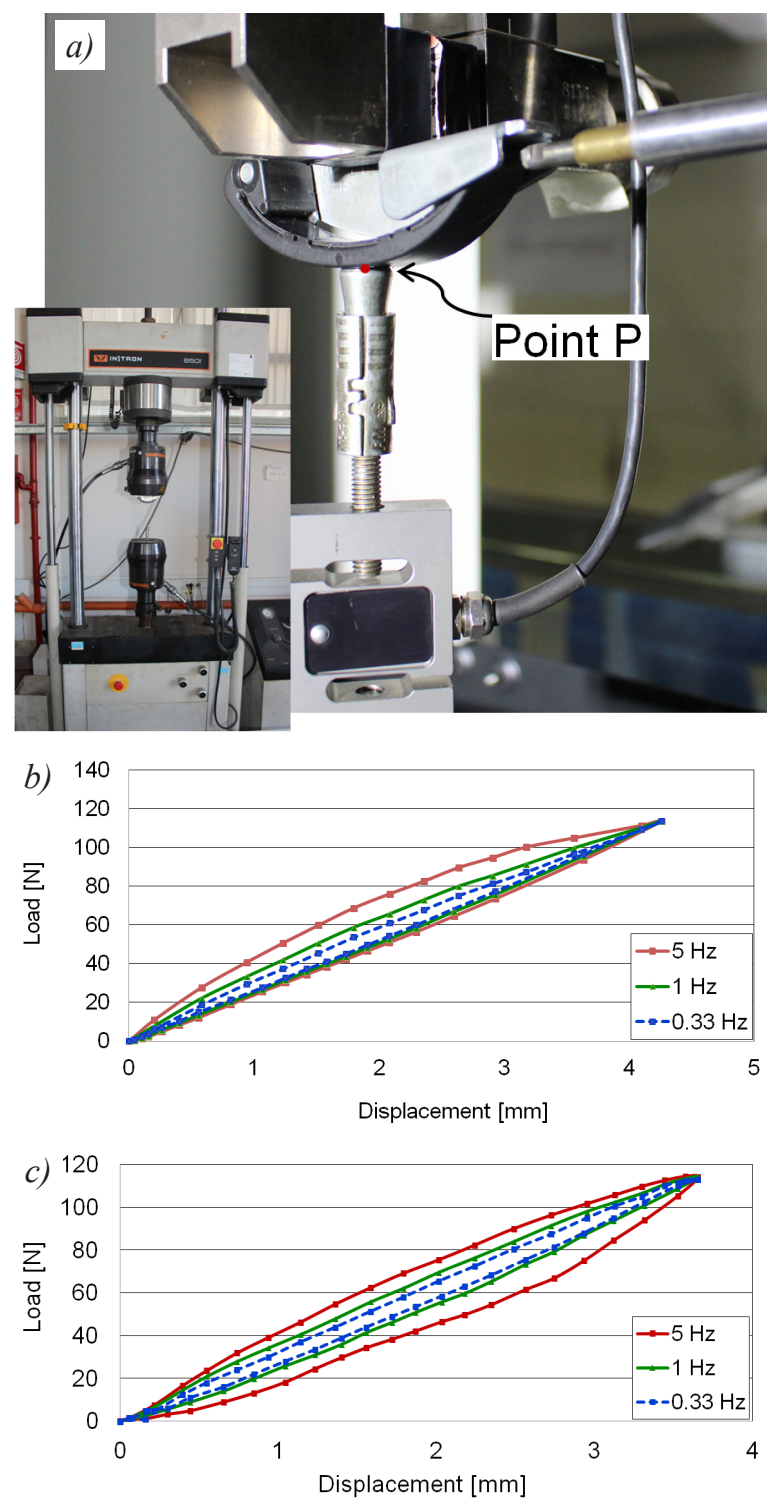

Fig. 11. Cyclic tests: a) strain gauge load cell and inductive HBM displacement transducers; b) transverse, and c) longitudinal displacement curves

Blade flexibility was characterized using cyclic load-unload tests at varying frequencies. Tests were carried out with lubricated leaf springs applying loads between preload $\left(F_{\text {pre }}=21.6 \mathrm{~N}\right)$ and maximum load $\left(F_{\max }=138.3 \mathrm{~N}\right)$ in the central area where the chain touches the tensioner (point P Fig. 11a) within the frequency range $0.01 \mathrm{~Hz}$ to $5 \mathrm{~Hz}$.

Displacement transducers measure transverse displacements $\left(D_{t}\right)$ in $x$ direction on point $\mathrm{P}$ of tensioner surface and lengthening (longitudinal displacements: $D_{1}$ in $y$ direction) at the blade tip along the bracket shelf (Fig. 11a).

The experimental setup includes: Instron 8501 servo-hydraulic dynamic testing machine and FastTrack 2 software; a $2 \mathrm{kN}$ A.S.T. $\mathrm{GmbH}$ Angewandte Systemtechnik strain gauge load cell with the sensitivity of $2 \mathrm{mV} / \mathrm{V}$; an inductive $\mathrm{HBM}$ vertical displacement transducer (WA20, $20 \mathrm{~mm}$, $<0.1 \%$ f.s.); an inductive HBM horizontal displacement transducer (WA50, $50 \mathrm{~mm},<0.1 \%$ f.s.); an HBM MgcPlus acquisition system (ADC 24bit).

The cyclic displacement curves were quite variable during the first cycles and were regularly repeated only after approximately twenty cycles; it is governed by the adopted frequency and maximum load. In Figs. $11 \mathrm{~b}$ and c, $D_{t}$ and $D_{1}$ versus fluctuating loads $\left(\Delta F=F_{\max }-F_{\text {pre }}=116.7 \mathrm{~N}\right)$ after twenty cycles at $0.33 \mathrm{~Hz}, 1 \mathrm{~Hz}$ and $5 \mathrm{~Hz}$ are outlined respectively.

In cycles with small fluctuating loads and low frequency the dissipated energy is negligible. For $\Delta F=116.7 \mathrm{~N}$ the hysteresis phenomenon becomes significant only at frequencies exceeding $0.33 \mathrm{~Hz}$. In order to quantify the tensioner damping, $D$ stands for the ratio between the dissipated energy per cycle $W_{D}$ and the equivalent elastic energy $W_{s}$ (green and blue areas respectively in Fig. 12):

$$
D=\frac{W_{D}}{W_{s}} .
$$

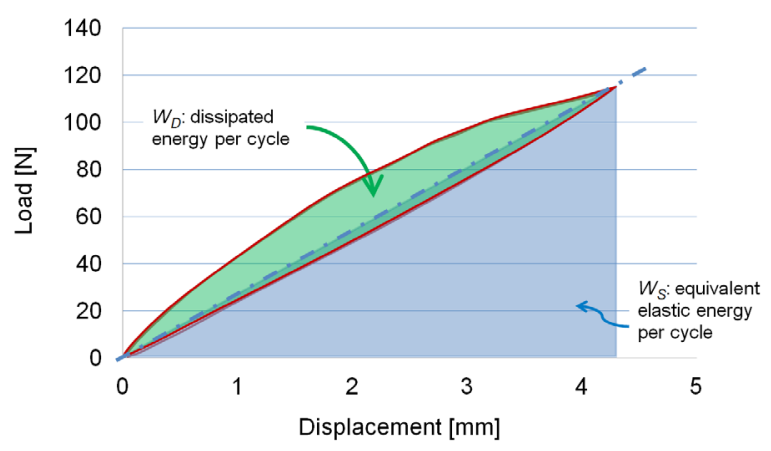

Fig. 12. Dissipated and equivalent elastic energy per cycle at $5 \mathrm{~Hz}$

Table 3 shows the dissipated energy per cycle $W_{D}$, the equivalent elastic energy $W_{s}$ and the damping 
factor $D$ evaluated in the areas where the cycles are regularly repeated at $0.01 \mathrm{~Hz}, 0.33 \mathrm{~Hz}, 1 \mathrm{~Hz}$ and $5 \mathrm{~Hz}$.

Values of $D, D_{t}, D_{1}$ and frequencies allow determining, with a DOE analysis, the best fitting stiffness $k^{i}$ and damping $c^{i}$ coefficient values for the 21 GF of the multibody model. Table 4 shows these values.

Table 3. Equivalent viscous damping coefficient

\begin{tabular}{cccc}
\hline Cycle freq. $[\mathrm{Hz}]$ & $W_{D}[\mathrm{~mJ} / \mathrm{cycle}]$ & $W_{s}[\mathrm{~mJ} /$ cycle $]$ & $D[-]$ \\
\hline 0.01 & 1.04 & 249.07 & 0.004 \\
\hline 0.33 & 16.43 & 248.95 & 0.066 \\
\hline 1 & 38.77 & 248.57 & 0.156 \\
\hline 5 & 73.77 & 248.39 & 0.297 \\
\hline
\end{tabular}

These coefficients allow obtaining a MBM-FDoF capable of accurate reproduction of the tensioner's dynamic behaviour. In Fig. 13 modal shapes in correspondence with mean load obtained with the MBM-FDoF are compared with those obtained with the FE model. The red geometry is the undeformed shape.

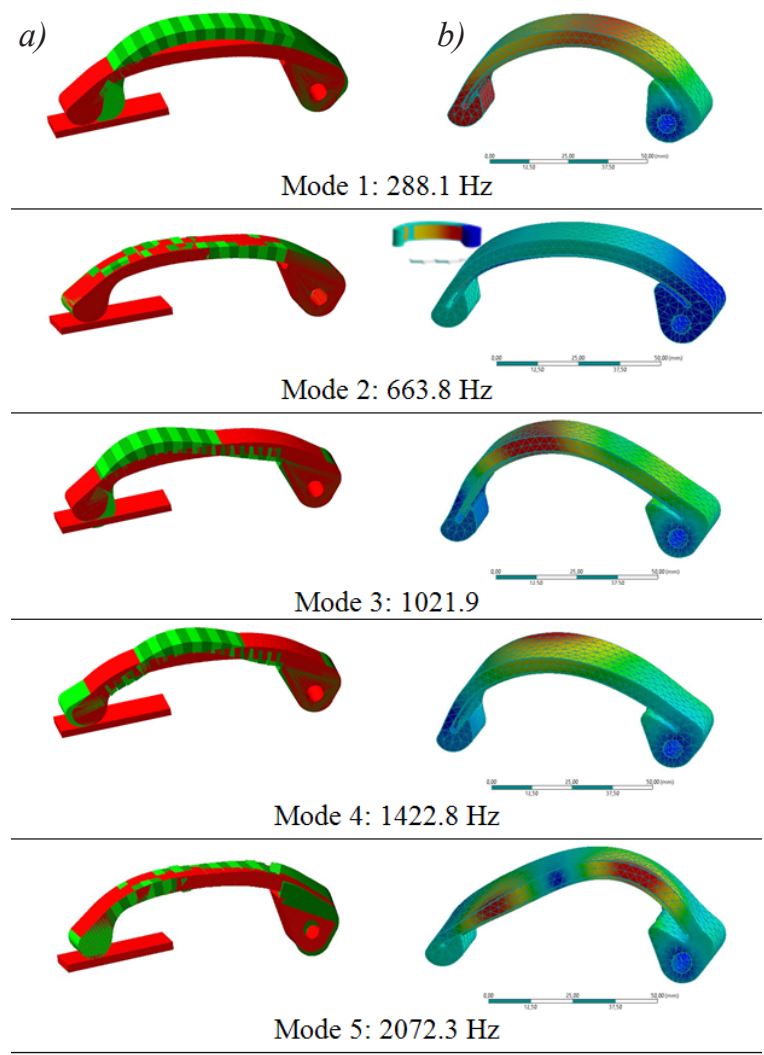

Fig. 13. Tensioner modal shapes $\left(F_{\text {mean }}=80 \mathrm{~N}\right)$ : a) MBM-FDoF; and b) FE model
Table 4. General-force stiffness and damping coefficients

\begin{tabular}{ccccc}
\hline GF & $\begin{array}{c}k_{x} \\
{[\mathrm{~N} / \mathrm{mm}]}\end{array}$ & $\begin{array}{c}k_{y} \\
{[\mathrm{~N} / \mathrm{mm}]}\end{array}$ & $\begin{array}{c}k_{z} \\
{[\mathrm{~N} / \mathrm{mm}]}\end{array}$ & $\begin{array}{c}c_{x} ; c_{y} ; c_{z} \\
{[\mathrm{~N} \cdot \mathrm{s} / \mathrm{mm}]}\end{array}$ \\
\hline GF1 to GF3 & $30 \mathrm{E}+06$ & $3.6 \mathrm{E}+06$ & $90 \mathrm{E}+06$ & 150 \\
\hline GF4 to GF18 & $30 \mathrm{E}+06$ & $4.2 \mathrm{E}+06$ & $90 \mathrm{E}+06$ & 150 \\
\hline GF19 to GF21 & $30 \mathrm{E}+06$ & $3.0 \mathrm{E}+06$ & $90 \mathrm{E}+06$ & 150 \\
\hline GF & $\begin{array}{c}k_{\vartheta} \\
{\left[\mathrm{N} \cdot \mathrm{mm} /{ }^{\circ}\right]}\end{array}$ & $\begin{array}{c}k_{\varphi} \\
{\left[\mathrm{N} \cdot \mathrm{mm} /{ }^{\circ}\right]}\end{array}$ & $\begin{array}{c}k_{\psi} \\
{\left[\mathrm{N} \cdot \mathrm{mm} /{ }^{\circ}\right]}\end{array}$ & $\begin{array}{c}c_{g} ; c_{\varphi} ; c_{\psi} \\
{\left[\mathrm{N} \cdot \mathrm{mm} \cdot \mathrm{s}^{\circ}\right]}\end{array}$ \\
\hline GF1 to GF3 & $1 \mathrm{E}+06$ & 2500 & 1490 & 3500 \\
\hline GF4 to GF18 & $1 \mathrm{E}+06$ & 2500 & 1960 & 3500 \\
\hline GF19 to GF21 & $1 \mathrm{E}+06$ & 2500 & 1490 & 3500
\end{tabular}

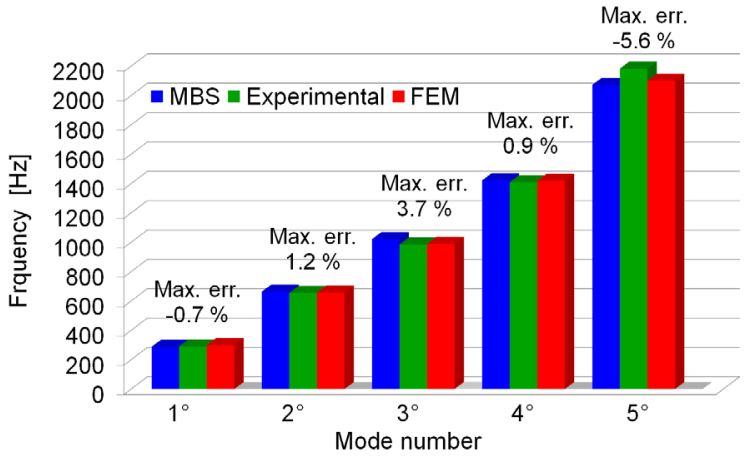

Fig. 14. Multibody model versus experimental and FE model frequencies $\left(F_{\text {mean }}=80 \mathrm{~N}\right)$
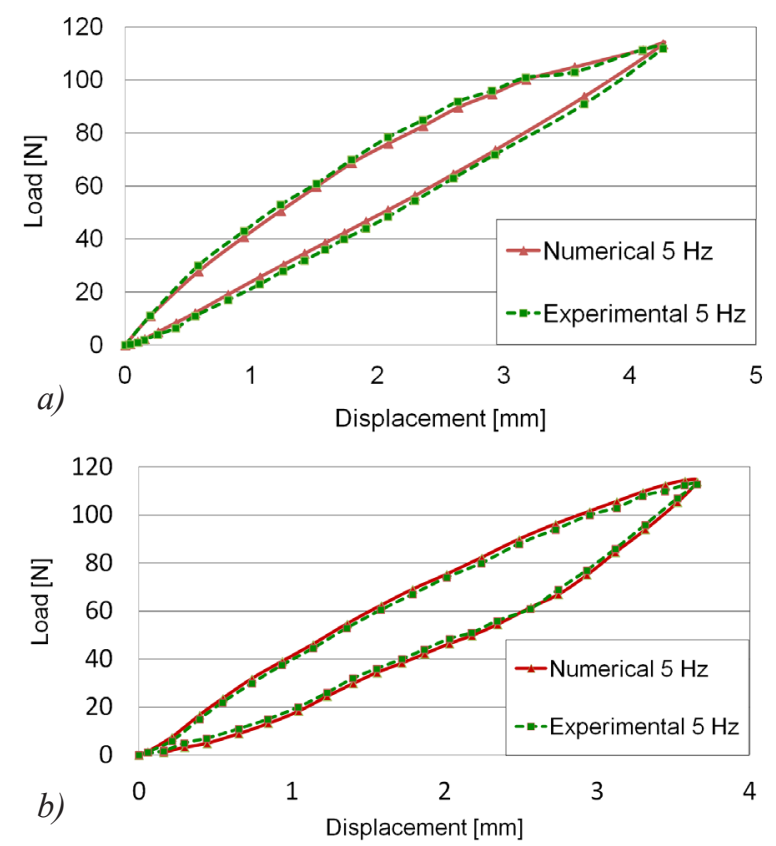

Fig. 15. Experimental versus numerical for a) transverse and b) longitudinal displacement curves

Fig. 14 shows the multibody model frequencies and percentage deviations from the experimental and 
FE model values in correspondence with mean load. MBM-FDoF reproduces the first five experimentally obtained frequencies with a maximum error of $5.6 \%$.

Fig. 15 compares experimental and numerical transverse and longitudinal displacement curves at 5 Hz. The maximum measured error was $3.4 \%$.

\section{CONTROLLING THE TENSIONER'S DYNAMIC BEHAVIOUR BY FUNCTIONAL TOLERANCES}

With the aim of evaluating the effects functional tolerance variations have on the tensioner dynamic behaviour, numerical simulations with FE tensioner model were performed modifying dimensions, geometries and interferences controlled by the tolerances outlined in Section 1.

Sensitivity analysis, conducted by loading the FE tensioner model with the above defined cyclic loads, indicates that the coupling between the three leaves and the both ends of the blade mostly influence the dynamic behaviour of the tensioner. It has been observed that also the coupling between the first leaf spring and the internal concave surface of the blade influences the dynamic behaviour of the tensioner and, in particular, the energy it dissipates.

The control of such couplings can be performed directly by means of profile tolerance values in F-G and H-L zones of the blade, as well as profile tolerances in G-H zone of the blade (Fig. 2), and profile tolerances on leaf spring (Fig. 5).

As long as the profile tolerances on leaf springs and blade remain within design values, the interference at the couplings of both ends can be exclusively considered as a function of initial static curvatures of leaf springs and blade. Leaf spring housings are designed to be larger than the widths of the leaf assembly (Fig. 16a). The difference in curvature between the leaves and their housing surfaces right from their initial assembly create an interference coupling (initial assembly interference) which undergoes little variations (functional interference) during tensioner operation (Fig. 16b). Hypothesising that the leaf housing deforms within the elastic limit of polyamide (and therefore also that of steel), the value of the initial assembly interference $i$ can be calculated by equaling the elastic force $F_{s}$ between the three leaf springs (Eq. (4)) to the elastic deformation force $F_{p}$ of the leaves housing (Eq. (5)):

$$
F_{s}=\frac{3 E_{s} I}{\left(\frac{L}{2}\right)^{3}} \delta_{s}=\frac{24 E_{s} I}{L^{3}} \delta_{s},
$$

$$
F_{p}=E_{p} \cdot \mathrm{A} \cdot \frac{i}{h_{r}},
$$

where $E_{s}$ and $E_{p}$ are Young's moduli for leaf spring and polyamide respectively, $I=b h^{3} / 12$ is the moment of inertia of the leaf springs cross-section (Fig. 16a), $\mathrm{d}_{s}$ is the difference in the transverse direction between the non-deformed spring height $h_{\text {undef }}$ and that of the leaf spring within its housing $h_{\text {def }}\left(\mathrm{d}_{s}=h_{\text {undef }}-h_{\text {def }}\right)$, $L=84 \mathrm{~mm}$ is the leaf spring length, A is the contact area between the leaf spring and its housing, $i$ is the interference and $h_{r}$ is the total resistant thickness of the housing (Fig. 17).

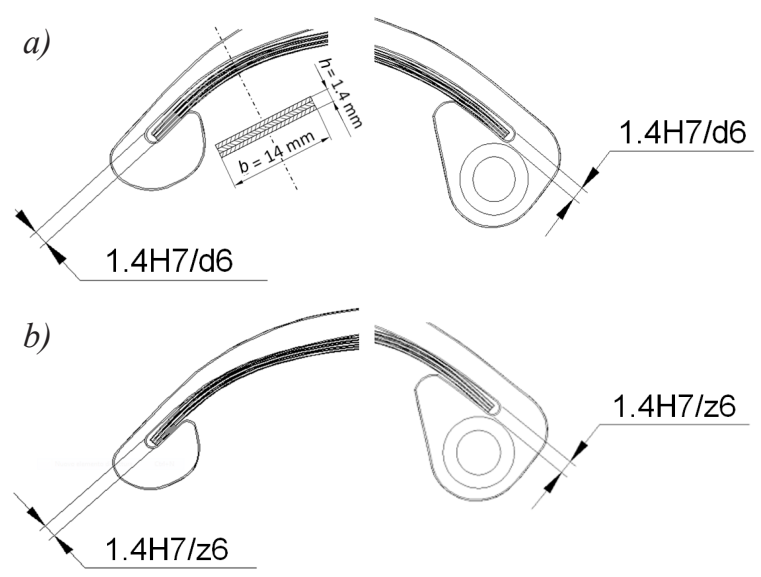

Fig. 16. Coupling between leaf springs and blade housing: a) design clearance; b) initial assembly interference

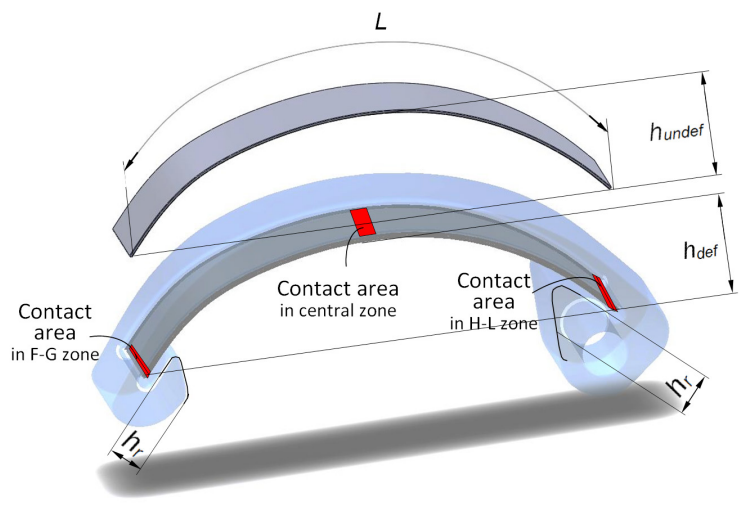

Fig. 17. Geometric parameters and contact areas in the couplings between leaf springs and blade

By substituting the geometric parameters and Young's modulus in Eqs. (4) and (5), assigning $h_{r}$ a value of $8 \mathrm{~mm}, \mathrm{~d}_{s}$ a value of $5 \mathrm{~mm}$ the minimum interference $i_{\min }$ and the maximum interference $i_{\max }$ values are function of contact area $\mathrm{A}$ values.

$$
i=\frac{24 E_{s} I}{L^{3} E_{p}} h_{r} \delta_{s} \cdot \frac{1}{\mathrm{~A}} .
$$




\subsection{Evaluation of Contact Areas}

As visible in Fig. 17 there are three contact areas between leaf springs and blade, but for the calculation of interference $i$ only the areas at the both ends of the blade (contact areas in F-G and H-L zones) must be taken into account. The FE model provides, during tensioner operation between preload $(F=21.6 \mathrm{~N})$ and maximum load $(F=138.3 \mathrm{~N})$, variable values of these contact areas between $7.1 \mathrm{~mm}^{2}$ and 14 $\mathrm{mm}^{2}$. In accordance with such values the minimum interference $i_{\min }=0.20 \mathrm{~mm}$ and the maximum interference $i_{\max }=0.38 \mathrm{~mm}$.

a)
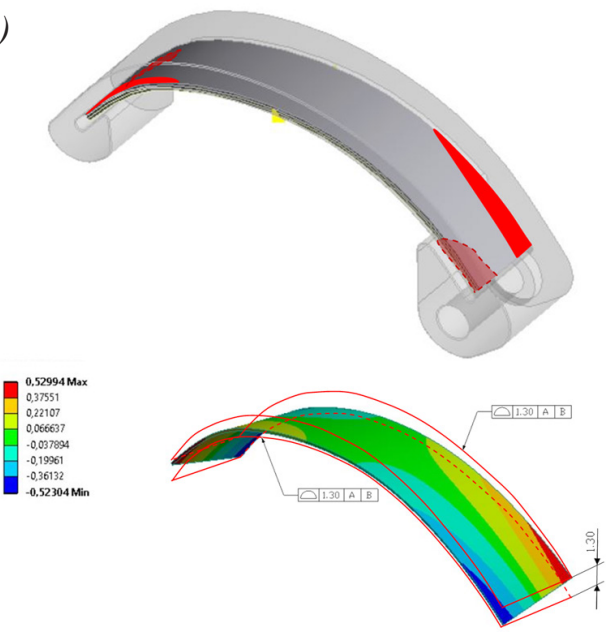

b)
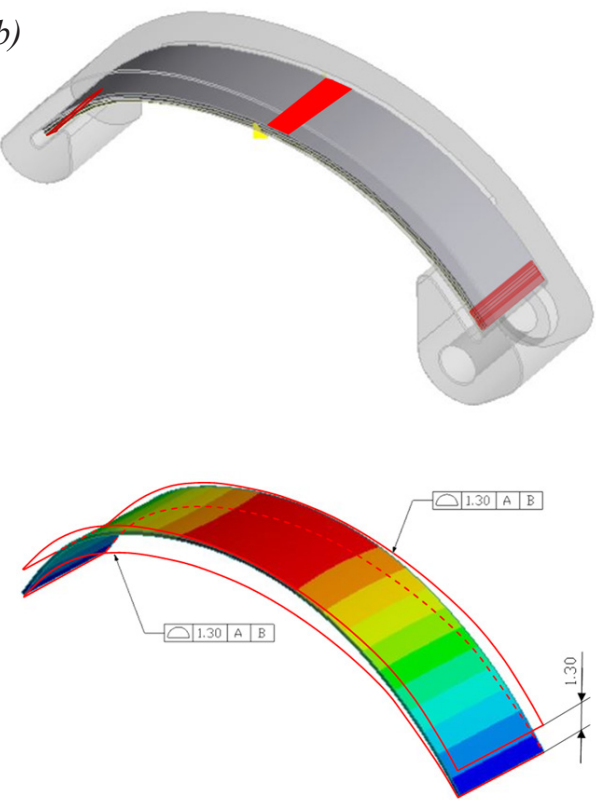

Fig. 18. Contact areas between leaf spring and blade for profile tolerance $1.3 \mathrm{~mm}$; a) maximum torsional error, and b) maximum flexional error
Tensioner's dynamic behaviour has been studied assigning to springs and blade a larger range of profile tolerance values than those fixed in the design in order to evaluate the effects that functional tolerance variations have on it.

In particular variations in the profile tolerance values in the F-G and H-L zones of the blade, as well as profile tolerances on the leaf spring produce changes in the maximum amplitude and position of the contact area A. Using the FE model the values of $\mathrm{A}$ and interferences $i$ during cyclic load-unload tests were evaluated. Fig. 18 shows, as an example, the values of contact areas in the F-G and H-L zones, estimated when the profile tolerances on the leaf spring equal $1.3 \mathrm{~mm}$. The figure also represents the two limit cases in which the leaf spring exclusively deforms torsionally or flexurally up to the maximum shape error allowed by the profile tolerance (Case 3 Table 5).

Table 5. Profile tolerance variations, contact area A and interference $i$

\begin{tabular}{|c|c|c|c|c|}
\hline & Case & Shape & Position & Orientation \\
\hline \multirow{9}{*}{$\begin{array}{c}\text { Blade } \\
\text { profile } \\
\text { tolerance } \\
\text { [mm] }\end{array}$} & 1 & 0.1 & 0.05 & 0.05 \\
\hline & 2 & 0.1 & 0.05 & 0.05 \\
\hline & 3 & 0.1 & 0.05 & 0.05 \\
\hline & 4 & 0.7 & 0.3 & 0.3 \\
\hline & 5 & 0.7 & 0.3 & 0.3 \\
\hline & 6 & 0.7 & 0.3 & 0.3 \\
\hline & 7 & 1.30 & 0.7 & 0.7 \\
\hline & 8 & 1.30 & 0.7 & 0.7 \\
\hline & 9 & 1.30 & 0.7 & 0.7 \\
\hline \multirow{9}{*}{$\begin{array}{l}\text { Leaf spring } \\
\text { profile } \\
\text { tolerance } \\
\text { [mm] }\end{array}$} & 1 & 0.05 & 0.05 & 0.05 \\
\hline & 2 & 0.7 & 0.3 & 0.3 \\
\hline & 3 & 1.3 & 0.7 & 0.7 \\
\hline & 4 & 0.05 & 0.05 & 0.05 \\
\hline & 5 & 0.7 & 0.3 & 0.3 \\
\hline & 6 & 1.3 & 0.7 & 0.7 \\
\hline & 7 & 0.05 & 0.05 & 0.05 \\
\hline & 8 & 0.7 & 0.3 & 0.3 \\
\hline & 9 & 1.3 & 0.7 & 0.7 \\
\hline \multirow{2}{*}{ Case } & \multicolumn{2}{|c|}{ Contact area [mm] } & \multicolumn{2}{|c|}{ Interference [mm] } \\
\hline & Min & $\operatorname{Max}$ & Min & $\operatorname{Max}$ \\
\hline 1 & 7.1 & 14.0 & 0.20 & 0.38 \\
\hline 2 & 6.7 & 19.5 & 0.14 & 0.41 \\
\hline 3 & 6.2 & 24.7 & 0.12 & 0.44 \\
\hline 4 & 6.8 & 21.1 & 0.14 & 0.40 \\
\hline 5 & 6.1 & 28.2 & 0.11 & 0.45 \\
\hline 6 & 5.5 & 35.5 & 0.09 & 0.51 \\
\hline 7 & 6.3 & 31.6 & 0.10 & 0.44 \\
\hline 8 & 5.4 & 38.7 & 0.08 & 0.51 \\
\hline 9 & 5.0 & 47.2 & 0.06 & 0.55 \\
\hline
\end{tabular}


Similarly it is possible to link position and orientation errors to values of contact areas $\mathrm{A}$ and interference $i$ in the F-G and H-L zones. Table 5 outlines contact areas A minimum and maximum values, as well as minimum interference $\left(i_{\min }\right)$ and maximum interference $\left(i_{\max }\right)$ values depending on the variation in profile tolerances on the leaf springs and blade.

The nine cases of tolerance combinations shown in Table 5 were obtained from three profile tolerance values $(0.1 \mathrm{~mm}, 0.7 \mathrm{~mm}$ and $1.3 \mathrm{~mm})$ for both blade ends and three profile tolerance values $(0.5 \mathrm{~mm}$, $0.7 \mathrm{~mm}$ and $1.3 \mathrm{~mm}$ ) for the leaf springs. The same variations in profile tolerance at both blade ends were hypothesized.

\subsection{Discussion of Results}

It has been observed that the variations in assembly interference $i$ values mainly influence the flexional moment values in xy plane of the GF $\left(\vec{F}_{\psi}^{i}\right)$ and the $D$ value. So to uphold the validity of the MBM-FDoF in a wide range of profile tolerances stiffness $k^{i}$ and damping $c^{i}$ coefficient values have to vary with $i$. To automatically retrieve stiffness $k^{i}$ and damping $c^{i}$ coefficient values for GF components the following analytic equation has been empirically derived:
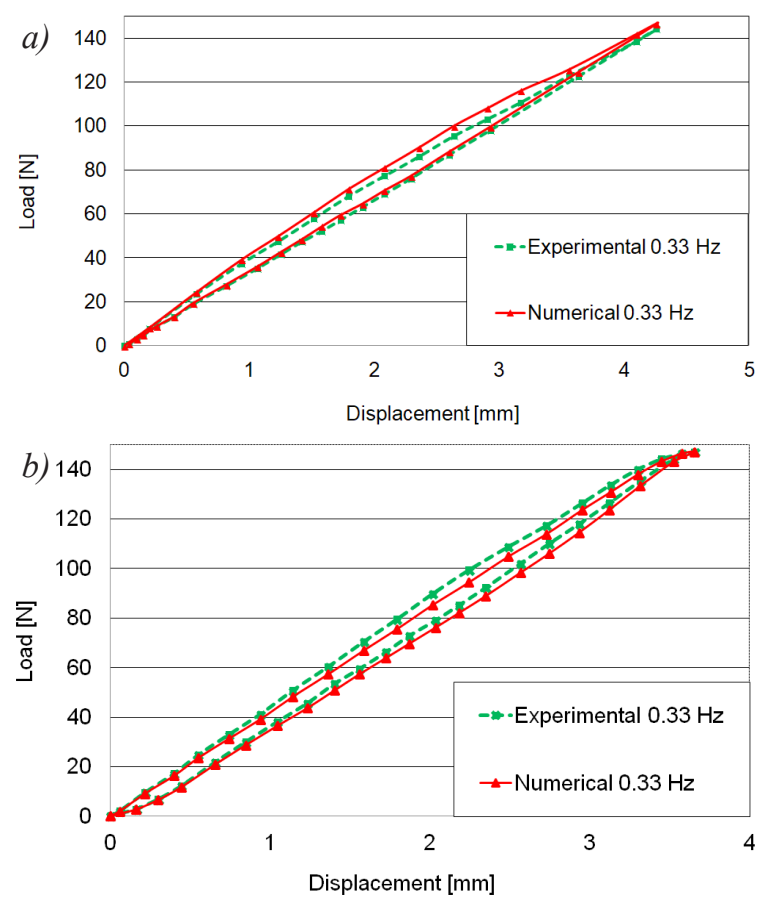

Fig. 19. a) Cyclic transverse and b) longitudinal displacement curves at $0.33 \mathrm{~Hz}, i_{\text {init }}=0.3 \mathrm{~mm}$

$$
\begin{aligned}
& k_{\psi}=k_{\psi \text { init }} e^{0.276 i}, \\
& c_{\psi}=c_{\psi \text { init }} e^{0.561 i},
\end{aligned}
$$

where $k_{\psi \text { init }}$ and $c_{\psi \text { init }}$ are stiffness and damping coefficients respectively in correspondence with design interference (Table 4).

As long as the variations in assembly interference are between $0.03 \mathrm{~mm}$ and $1.3 \mathrm{~mm}$, MBM-FDoF enables monitoring tensioner dynamic performances in correspondence with different functional tolerances. Figs. 19 and 20 show experimental and numerical cyclic transverse and longitudinal displacement curves at $0.33 \mathrm{~Hz}$ and $5 \mathrm{~Hz}$ corresponding to an initial assembly interference values $i_{\text {init }}=0.3 \mathrm{~mm}$.

The experimental curves were obtained, inserting small calibrated thickness in stainless steel within the couplings between leaf spring and ends of the blade, thus reproducing the desired interference values (Fig. 21). In particular thickness from $0.4 \mathrm{~mm}$ to $0.6 \mathrm{~mm} \pm$ $0.02 \mathrm{~mm}$ (measured with caliber) was used to perform experimental measures.

Highlighting principal results obtained MBM FDoF is able to predict transverse and longitudinal displacement of the tensioner, as well as the dissipated energy due to variations in functional tolerances. Fig.
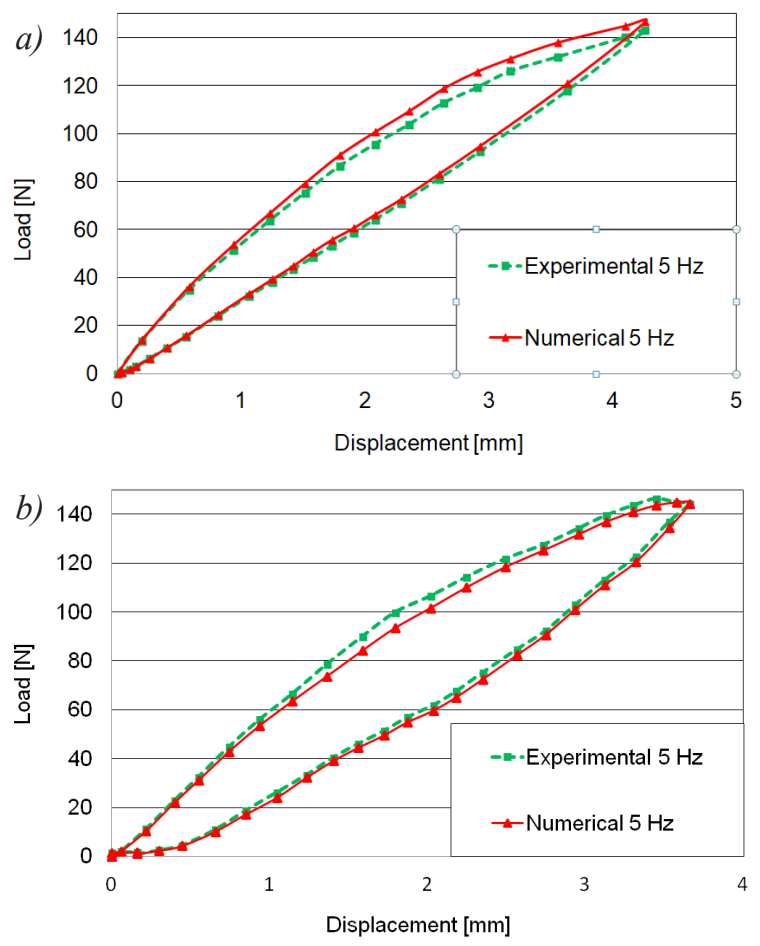

Fig. 20. a) Cyclic transverse and b) longitudinal displacement curves at $5 \mathrm{~Hz}, i_{\text {init }}=0.3 \mathrm{~mm}$ 
22 shows experimental and numerical transverse displacement of the point $\mathrm{P}$ (evidenced in Fig. 11a) during the most critical accelerating transient condition (sweep $1000 \mathrm{rpm}$ to $8000 \mathrm{rpm}$ in $0.7 \mathrm{~s}$ ) [9].
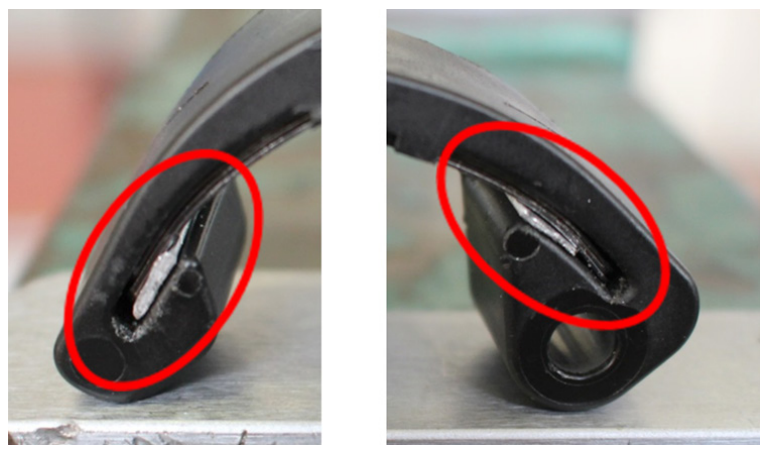

Fig. 21. Calibrated thickness within the couplings between leaf spring and ends of the blade

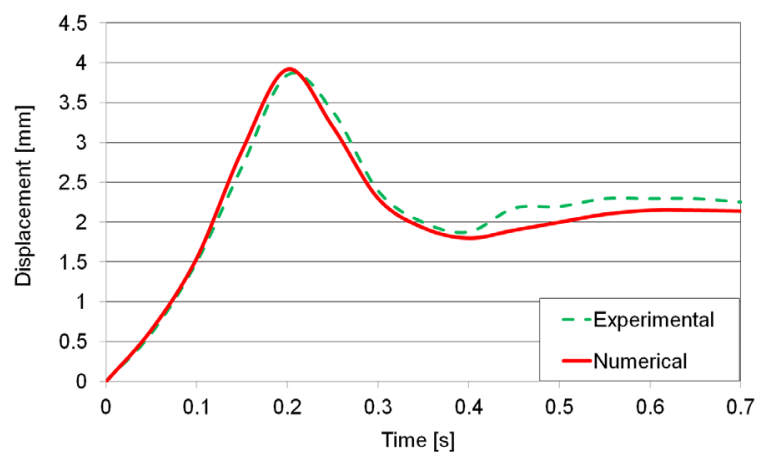

Fig. 22. Tensioner transverse displacement during acceleration transient condition (sweep $1000 \mathrm{rpm}$ to $8000 \mathrm{rpm}$ )

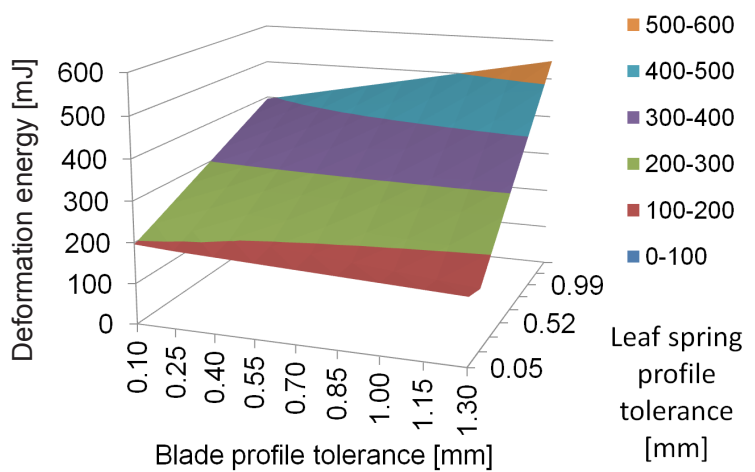

Fig. 23. Deformation energy vs blade profile tolerance and leaf spring profile tolerance

Fig. 23 shows the dissipated deformation energy per cycle as function of blade profile tolerance and leaf spring profile tolerance. It indicates that the leaf spring profile tolerance mostly influence dissipated energy especially for high blade profile tolerance. Table 6 summarizes the obtained dissipated energy for the nine cases of tolerance combinations shown in Table 5 .

Table 6. Dissipated deformation energy

\begin{tabular}{cc}
\hline Cases & WD [mJ/cycle] \\
\hline 1 & 196.2 \\
\hline 2 & 245.4 \\
\hline 3 & 295.1 \\
\hline 4 & 178.3 \\
\hline 5 & 225.0 \\
\hline 6 & 306.9 \\
\hline 7 & 162.1 \\
\hline 8 & 319.4 \\
\hline 9 & 547.5 \\
\hline
\end{tabular}

\section{CONCLUSIONS}

GD\&T was used to control the influence of functional tolerances on the dynamic behaviour of a mechanical tensioner. The study demonstrates how ASME and ISO tolerance standard specifications can be used to control the conformity of an assembled system composed of flexible components with functional requirements. The method, based on experimental modal analyses and displacement measurements, can be used to predict the effects of assembly and utilization errors on dissipated deformation energy and on flexibility.

Multibody models with few degrees of freedom can be used to precisely predict and control the effects functional tolerance variations have on the tensioner's dynamic behaviour. In particular the energy the tensioner dissipates was measured and the interrelationship with the most influential tolerances was established

This methodology can be applied to many different types of assembled systems with flexible components, including compliant and biomechanical systems.

\section{ACKNOWLEDGEMENTS}

The authors would like to express profound gratitude to the "Direzione Tecnica Motopropulsori Ferrari S.p.A." and its former director Eng. Agostino Dominici for the provided data and invaluable collaboration.

The present research was carried out within the framework of the project AMELIE-Advanced framework for Manufacturing Engineering and product Lifecycle Enhancement, code: PON03PE_00206_1. 


\section{REFERENCES}

[1] Woo, S. (2017). Reliability Design of Mechanical Systems: A Guide for Mechanical and Civil Engineers. Springer, Cham, DOI:10.1007/978-3-319-50829-0.

[2] Tapia-González, P.E., Ledezma-Ramírez, D.F. (2017). Experimental characterisation of dry friction isolators for shock and vibration. Journal of Low Frequency Noise, Vibration and Active Control, vol. 36, no. 1, p. 83-95, DOl:10.1177/0263092317693509.

[3] Wei, C., Sun, J., Xin-min L. (2014). Tolerance Optimization Considerations Applied to the Sheet Metal Compliant Assembly. Computer Aided Design and Applications, vol. 11, suppl. 1, S68-S76, Dol:10.1080/16864360.2014.914413.

[4] Cappellini, N., Tamarozzi, T., Blockmans, B., Fiszer, J., Cosco, F., Desmet, W. (2017). Semi-analytic contact technique in a non-linear parametric model order reduction method for gear simulations. Meccanica, vol. 53, no. 1-2, p. 49-75, DOI:10.1007/s11012-017-0710-5.

[5] Zeng, X.K., Wang, H.Y. (2014). Experimental and modelling analysis of dynamic characteristic for automatic tensioner in a two pulley-belt drive system. International Journal of Vehicle Noise and Vibration, vol. 10, no. 4, p. 302-314, Dol:10.1504/ IJVNV.2014.065635.

[6] Valentini, P.P., Pezzuti, E. (2016). Computer-aided tolerance allocation of compliant ortho-planar spring mechanism. International Journal of Computer Applications in Technology, vol. 53, no. 4, p. 369-374, D0I:10.1504/IJCAT.2016.076801.

[7] Hu, S., Guo, X. (2015). A dissipative contact force model for impact analysis in multibody dynamics. Multibody System Dynamics, vol. 35, no. 2, p. 131-151, Dol:10.1007/s11044 -015-9453-z.

[8] Calì, M., Oliveri, S.M., Sequenzia, G., Fatuzzo, G. (2017). An effective model for the sliding contact forces in a multibody environment. Lecture Notes in Mechanical Engineering, p. 675-685, DOI:10.1007/978-3-319-45781-9_68.

[9] Calì, M., Sequenzia, G., Oliveri, S.M., Fatuzzo, G. (2016). Meshing angles evaluation of silent chain drive by numerical analysis and experimental test. Meccanica, vol. 51, no. 3, p. 475-489, D0l:10.1007/s11012-015-0230-0.

[10] Sequenzia, G., Oliveri, S.M., Calï, M. (2013). Experimental methodology for the tappet characterization of timing system in I.C.E. Meccanica, vol. 48, no. 3, p. 753-764, Dol:10.1007/ s11012-012-9629-z.

[11] ASME Y14.5 (2009). Dimensioning and Tolerancing. The American Society of Mechanical Engineers, New York.

[12] ISO 1101 (2017). Geometrical product specifications (GPS)Geometrical tolerancing - Tolerances of form, orientation, location and run-out. International Organization for Standardization, Geneva.

[13] Ameta, G., Serge, S., Giordano, M. (2011). Comparison of spatial math models for tolerance analysis: Tolerance-maps, deviation domain, and TTRS. Journal of Computing and Information Science in Engineering, vol. 11, no. 2, p.1-8, DOI:10.1115/1.3593413.
[14] Ambu, R. (2013). A method with a statistical approach for the evaluation of tolerance chains. Advanced Materials Research, vol. 651, p. 601-606, D0l:10.4028/www.scientific.net/ AMR.651.601.

[15] Dantan, J-Y., Mathieu, L., Ballu, A., Martin, P. (2005). Tolerance synthesis: quantifier notion and virtual boundary. ComputerAided Design, vol. 37, no. 2, p. 231-240, D0l:10.1016/j. cad.2004.06.008.

[16] Anselmetti, B. (2006). Generation of functional tolerancing based on positioning features. Computer-Aided Design, vol. 38, no. 8, p. 902-919, D0l:10.1016/j.cad.2006.05.005.

[17] Huang, W., Phoomboplab, T., Ceglarek, D. (2009). Process capability surrogate model-based tolerance synthesis for multi-station manufacturing systems. IIE Transactions, vol. 41, no. 4, p. 309-322, D0l:10.1080/07408170802510408.

[18] Kleiner, M., Geiger, M., Klaus, A. Manufacturing of lightweight components by metal forming. CIRP Annals-Manufacturing Technology, vol. 52, no. 2, p. 521-542, D0l:10.1016/S00078506(07)60202-9.

[19] Dieter, G.E., Bacon, D.J. (1986). Mechanical Metallurgy (vol. 3), McGraw-Hill, New York.

[20] Fredriksson, H., Åkerlind, U. (2006). Materials Processing during Casting (vol. 210). Wiley, Chichester, DOI:10.1002/9780470017920.

[21] Neikov, O.D., Murashova, I.B., Yefimov, N.A., Naboychenko, S. (eds.) (2009). Handbook of Non-Ferrous Metal Powders: Technologies and Applications. Elsevier, Oxford.

[22] Davidson, J.K., Mujezinovic ,A., Shah, J.J. (2002). A new mathematical model for geometric tolerances as applied to round faces. Journal of Mechanical Design, vol. 124, no. 4, p. 609-622, Dol:10.1115/1.1497362.

[23] Fiszer, J., Tamarozzi, T., Desmet, W. (2016). A semi-analytic strategy for the system-level modelling of flexibly supported ball bearings. Meccanica, vol. 51, no. 6, p. 1503-1532, Dol:10.1007/s11012-015-0318-6.

[24] Machado, M., Moreira, P., Flores, P., Lankarani, H.M. (2012). Compliant contact force models in multibody dynamics: Evolution of the Hertz contact theory. Mechanism and Machine Theory, vol. 53, p. 99-121, Dol:10.1016/j. mechmachtheory.2012.02.010.

[25] Calì, M., Oliveri, S.M., Fatuzzo, G., Sequenzia, G. (2017). Error control in UAV image acquisitions for 3D reconstruction of extensive architectures. Lecture Notes in Mechanical Engineering, p. 1211-1220, Springer, Cham, DOl:10.1007/978-3-319-45781-9_121.

[26] Wu, H.T., Mani, N.K., Ashrafiuon, H. (1995). Selection of modal basis for flexible bodies of mechanical systems. Mechanism and Machine Theory, vol. 30, no. 3, p. 471-489, DOI:10.1016/0094-114X(93)E0018-2.

[27] Fischer, M., Eberhard, P. (2015). Application of parametric model reduction with matrix interpolation for simulation of moving loads in elastic multibody systems. Advances in Computational Mathematics, vol. 41, no. 5, p. 1049-1072, D0l:10.1007/s10444-014-9379-7. 